\title{
TECHNOLOGICAL ENTREPRENEURSHIP FOR ECONOMIC DEVELOPMENT IN SOUTH EAST ASIAN COUNTRIES - A CASE OF MALAYSIA, SINGAPORE AND THAILAND
}

\author{
Uma Gunasilan \\ Associate Professor, Hult International Business School, London, U.K., \\ \& Faculty of Applied and Human Sciences, Universiti Perlis Malaysia
}

Norshahrizan Nordin

Associate Professor, Faculty of Applied and Human Sciences, Universiti Perlis Malaysia

Tunku Salha Tunku Ahmad

Associate Professor, Faculty of Applied and Human Sciences, Universiti Perlis Malaysia

Julinawati Suanda

Senior Lecturer, Faculty of Applied and Human Sciences, Universiti Perlis Malaysia

\begin{abstract}
Digital transformation is the profound transformation of business activities and processes to access the changes and opportunities evolved from the new generation of technology and their positive impact. Accordingly, organizations which implement digital transformation are often rewarded by increases in productivity, profit margins and market share. Basic principles and theories of digital transformation lead to a profitable and constructive business model and procedures. In this regard, the basic principle of digital transformation emphasizes on maintenance of data security, customer centricity as well as developing agility of business technologies. Similarly several researchers have focused on technological entrepreneurs, their capabilities and innovation; while some have emphasized on the relation between digital transformation and technological entrepreneurs and on the impact of the former on the latter. However, no specific research has been conducted on the impact of the fusion of digital transformation and technological entrepreneurship on the organizational performance. Thus, this study focuses on the role and impact on the performance of organizations on adopting digital transformation and technological entrepreneurship. The research primarily emphasizes on the South Asian countries, namely, Malaysia, Thailand and Singapore to study the digital transformation and organizational performance of technological entrepreneurship.
\end{abstract}


Key words: Digital Transformation, Technological Entrepreneurship, Organizational Performance.

Cite this Article: Uma Gunasilan, Norshahrizan Nordin, Tunku Salha Tunku Ahmad and Julinawati Suanda, Technological Entrepreneurship for Economic Development in South East Asian Countries - A Case of Malaysia, Singapore and Thailand, International Journal of Management, 11(12), 2020, pp 30-40.

http://iaeme.com/Home/issue/IJM?Volume=11\&Issue=12

\section{INTRODUCTION}

Any nation that has some traits of a developed high income economy but not meeting the operational benchmarks of a fully developed economy, effectively describes the term 'emerging economy' [1]. Economies that are still emerging are said to be in a phase of transition from developing to developed and may not fall in the category of newly industrialized economies or the poorest economies but do hold the promise of emerging as an economy that is fully developed. Over the past several decades, there has been a dramatic shift in the global economic landscape [2]. There has been a major transformation within the global economy where emerging economies have shifted from being a minor player a few decades back to an economy that is presently controlling the economic growth of the world owing to their commercial activities, population and economic outputs. As per predictions, nine out of the fifteen largest economies of the world in 2050 from the gross domestic product (GDP) aspects will be dominated by what is now known as emerging economies [3]. Economists, the world over are discussing about a new economic world order where emerging economies would be controlling the economy of the world in the near future [4].

The region of South East Asia is considered as a dynamic region of the world. A wider long-term view on the economic performance of this region indicates that the output delivered by South East Asia on the whole has risen by a decent average yearly rate of $5.4 \%$ over the past three decades [5]. The growth in GDP in South East Asia is superseded only by the growth rate of East Asia which is said to be around 8.6\%. This was attributed to the extraordinary dynamism of the People's Republic of China and a robust performance by nations such as Korea emerged as the major growth drivers, which in recent times, was said to be $6.1 \%$ [6]. However, South East Asia, in the long-run emerged to be much more dynamic as compared to other regions of the world such as Europe, North America or Latin America. There was acceleration in terms of growth during the first part of the 1990s, however, the financial crisis that South East Asia experienced during the late 1990s had far-reaching and in certain aspects a long-lasting impact on the region [7]. The rate of growth during the second half of 2000s dropped behind that of a newly dynamic South Asia. Irrespective of these setbacks, the GDP of South East Asia is presently higher by five times as compared to what it used to be in 1980 and continues to grow at a fairly decent rate [8].

Several factors were instrumental in reinforcing and supporting the economic growth in South East Asian region. The main reasons being high foreign demand for their export products and high rate of domestic savings. The demand for export from South East Asian nations such as Singapore, Malaysia and Thailand were from nations such as the United States [9]. The strategies in these South East Asian nations though had similarities to Japan but they were also substantially different from Japan as they also depended on foreign direct investments (FDI) [10]. FDIs were required by the South East Asian nations to underpin their phase of early industrialization and their shift to manufacturing from resource based production [13]. Akin to external demand, FDI was also largely from the United States [8]. The openness of the newly industrializing economies from this region towards FDI rendered 
it possible for multinational organizations to achieve low costs in terms of labor as it supported their global assembly operations [8].

During the course of the past ten years, economies that are presently emerging have been known to drive economic growth globally in a manner that is highly significant. Economies that are on the cusp of emergence such as Singapore, Thailand and Malaysia is said to contribute to exports in these nations which is inclusive of exports in technology [11]. In tandem with the trend, governments in such emerging economies are according much significance on technological entrepreneurship where they provide due support in terms of augmenting capital investments and extending support through favourable policies [3]. Considering the managerial and policy implications, it is imperative to comprehend the intricate link between socio-economic change and technological entrepreneurship [12].

The concept of technological entrepreneurship was initially proposed during the course of a seminar at Purdue University [16]. Technological entrepreneurship is now perceived as a critical manner through which technological innovations can be commercialized [17]. It could either be through the creation of a novel business unit or by setting up a new endeavor in an organization that is already in existence. Therefore, technological entrepreneurship converts potential technologies into those that add value. In the present times, several scholars have widely advocated and extended this concept. Technological entrepreneurship is kind of business leadership style that recognizes commercial opportunities that have tremendous potential and is highly intensive in terms of technology. It is also said to amass resources like capital and talent while managing substantial risks and robust growth using decision-making skills that are based on principles. Technological entrepreneurship is deemed as an investment in project which is used to assemble and execute heterogeneous assets and specialized individuals that are closely associated with developments in technological and scientific knowledge which is leveraged for creating and capturing value [13]. Hence, more effective utilization of augmenting new assets, competitiveness and innovation can result in the development of techno-based products and services [14].

The dynamics of technological entrepreneurship in the fast emerging region of South East Asia necessitates governments and organizations to respond to the changes with flexibility with a view to leverage such transition [15]. The region of South East Asia is experiencing rapid growth boosted by technological entrepreneurship and also due to the creation of the ASEAN Economic Community (AEC) [16]. Nations that fall under the AEC are a congregation of nations that range from a nation like Singapore which is fully developed to Myanmar that has recently adopted the concept of foreign investments [17]. Owing to the widespread and consistent economic growth in South East Asia and the easy availability of broadband internet and $3 \mathrm{G}$, a drop in prices of smartphones and continuous growth in terms of spending in research and development, technological entrepreneurship is boosting the start-up community in major regions of South East Asia [18]. Singapore, being the most developed amongst South East Asian regions is in the leading position owing to strong governmental support and favourable laws [19]. Similarly, nations such as Thailand and Malaysia are fast catching up.

This paper attempts to explore how technological entrepreneurship facilitates economic development in South East Asian countries.

\section{TECHNOLOGICAL ENTREPRENEUSHIP}

\subsection{In Malaysia}

The heavy focus of the Malaysian government on industrialization in the 1980s led to the growth of the manufacturing sector and subsequently, the creation and execution of government programme and public policies shifted the economy from one that was labour 
intensive manufacturing to high technology with value added initiatives that yielded higher returns [20]. Development of Malaysia from a historical perspective was based on the policy related to technological innovation having a wider setting of industrial policy and economic development [21]. Economic planning in Malaysia featured science and technology right from 1986 which was historic as the First National Science and Technology Policy was formulated then and was integrated as a unique component of the $5^{\text {th }}$ Malaysia Plan [22]. The vision for 2020 that was developed by Malaysia, forms their blueprint for an economy that is knowledge-based. An innovative structure to smoothen the science and technology governance was outlined in their Tenth Malaysia Plan [23]. The increased focus of Malaysia on science and technology led to technological developments which further fuelled technological entrepreneurship and eventually resulted in economic development of the nation.

The rapid pace of development of technology in Malaysia has stimulated small and medium sized businesses (SMEs) to leverage the opportunity to expand, establish and prosper their businesses [24]. Widespread involvement of Malaysian SMEs in revenue generation has indicated that they are in a position to create opportunities for employment, mobilize local resources, establish a society that is affluent and balanced and play a major supplementary role to large firms, ultimately reinforcing the nation's economic development on the whole [25]. The Malaysian government encouraged the growth of technological entrepreneurs by setting up technology parks, multimedia super corridors (MSC) and incubators that extended help to start-up organizations [26]. A key example would comprise of SIRIM Malaysia incubator hub located at Sepang that has been setup with several objectives out of which one of them would relate to extending aid to technological entrepreneurs to create concepts that are innovative, enhance knowledge and upgrade their skills [27].

\subsection{In Singapore}

The popular belief not long ago within business communities in Singapore was that the nation lacked entrepreneurship. But rather, it was appropriate to say that Singapore initially lacked in technological entrepreneurs which was mainly owing to two reasons. First and foremost was that there was a dearth of industrial heritage during the period before independence in 1965 [28]. The second was the fact that at the tertiary level, technical education only commenced during 1980s [29]. An individual, who is a graduate in technical education, requires several years before he or she can gain adequate experience to commence a business with adequate scope for survival [30]. The government in Singapore was also aware of this challenge and reiterated the fact that Singapore was in need of a favourable environment that allowed more number of Singaporeans to channelize their techno-based entrepreneurial skills to leverage the immense opportunities presented by the modern global economy [31].

Irrespective of these two reasons, Singapore did have technological entrepreneurs who initiated business immediately after Singapore commenced the process of industrialization. Several technological entrepreneurs commenced their own businesses following their work with multinational organizations and gained manufacturing experience. A large number of these technological entrepreneurs commenced businesses that were low risk such as providing support to multinational organizations in Singapore in the capacity of manufacturing subcontractors [32]. The consistent initiatives by the technological entrepreneurs in Singapore over a period of the past 30 years helped them to setup a robust array of supporting industries in engineering, electronics, computer software, plastics and rubber, automation equipment and metals [33]. Establishments that achieved high degree of success transitioned into contract manufacturers who were not just involved in manufacturing but in designing products too. A small number of such contract manufacturers were owned by foreign firms but since they 
were not managed properly, local employees brought it and thrived by turning the operations around through their technological entrepreneurship [34].

In Singapore, several initiatives were undertaken by the government to foster the growth of technological entrepreneurs. For example, Singapore has nurtured technopreneurism as a social initiative that is designed such as to bring about a radical transition in orientations such as increased innovation [35]. Further, the government created conditions that were quite favorable that facilitated the growth of technological entrepreneurs by offering a robust system of education, internet access and infrastructure

\subsection{In Thailand}

Thailand has over the years emerged as one amongst the developing nations that is most successful. Over the past several decades, Thailand witnessed a robust economic development. The average growth rate in Thailand was recorded at 8\% during $1976-1996$ [35]. As per a recent report, the degree of technological entrepreneurship was quite in Thailand as compared to developing nations within South East Asia. Within the South East Asian region, Thailand scored $18.9 \%$ which is said to be the highest degree of technological entrepreneurial activities [36]. This achievement of being recognized as a nation with the highest technological entrepreneurial activity is partly attributed to extensive support and encouragement from the government in Thailand. The government accords high priority from a national government level for technological entrepreneurs who are new and on the growth curve. Subsequent to the economic crisis that the nation faced in 1997, many organizations had to drastically downsize their operations or shut down operations entirely [37]. The government understood that technological entrepreneurship held the key for a possible solution and extended support to innovation in technological entrepreneurship [38]. In Thailand, activities related to technology transfer are more prevalent amongst hightechnology entrepreneurs. Though they are not actively involved in the development of key technologies but they are the ones who practice or execute such technologies. For instance, Sun Microsystem and Microsoft based out of the United States are responsible for the development of key technologies such as J2EE and .NET for information technology oriented business [39]. However, a large number of technological entrepreneurs in Thailand are responsible to implement such technologies. This also results in innovative growth of the economy through partnership or alliance strategy.

Government in Thailand also recognized the potential of technological entrepreneurship and considering its scope and implications on national economy, they formulated and implemented several favourable policies. The Thai government announced tax incentives for research and development (R\&D) activities. Tax incentives that were founded on the expenditure for $R \& D$ spending enabled entrepreneurs to deduct increased expenses for tax objectives as compared to what they actually spent [40]. The nation evaluated organizations that were keen to apply for tax incentives on R\&D that was based on project-to-project. This facilitated more technopreneurs to venture into business, leveraging technology and innovation.

The National Innovation Agency (NIA) in Thailand provides grant schemes that extend support to an extent of $75 \%$ on expenses that would be incurred in pilot-scale activities of an organization and prototyping. As compared to grant agencies in other nations, Thailand provides small grants around $\$ 160,000$ for a three year period [41]. During the period between 2003-2007, they provided grants to56 projects [42]. However, there was a substantial progress in the number of projects that were provided 56 to 552 grants during the period of 2010-2014. In recent times, the focus of the NIA has shifted to strategic sectors of technology business, solutions and designs [43]. The NIA in 2011 adopted the idea of an innovation 
coupon' that provides grants to private organizations which is equal to $90 \%$ of the project cost. This is done with a view to hire technological services which can be for implementing pilot projects. The NIA is supported in this endeavour by the Federation of Thai Industries that is considered as the largest association for manufacturers.

\section{RATIONALE}

Though there have been several studies that have been conducted in the past pertaining to entrepreneurship, technological entrepreneurship, economic growth and development, there are scant studies that explore the relation between technological entrepreneurship and economic growth. While there are ample studies that explore the relation between technological entrepreneurship and economic development in China, there are no studies that explore the link between the two for South East Asian nations such as Singapore, Malaysia and Thailand. This research will therefore play a crucial role in justifying how technological entrepreneurship can make an impact on economic growth of the nation. In addition, this research will also add to the existing body of work that will help future researchers.

\section{METHODOLOGY}

The researcher will attempt to find scholarly papers that are relevant to the current research by using appropriate keywords and a combination of keywords for optimum results. The papers will be checked for validity and reliability and only empirical papers that are pertinent to Singapore, Thailand and Malaysia will be included. Other papers that refer to South East Asia in general will also be considered sparingly.

In addition, this research is entirely based on secondary research where research conducted in the past on similar themes will be reviewed and analyzed. Based on this analysis, further primary research will be conducted that would explore the topic from an empirical perspective. The empirical papers will add much credibility and authenticate the findings of this secondary research.

\subsection{Contribution of Technological Entrepreneurship to Economic Development}

The most significant element of an ecosystem of technological entrepreneurship revolves around the entrepreneur itself. The entrepreneur is the main catalyst in the emergence of growth in business processes and economy. Technological entrepreneurs are known to possess more technological competencies and skills as compared to non-technical ones, for instance business related skills [40]. A key step in the success of any entrepreneurial endeavour would involve the transition of an entrepreneurial mind into a managerial mind. Technological entrepreneurs have to understand the process of leveraging technology to facilitate business evolution and the significance of entrepreneurial skills [14]. In addition, it is also imperative that they have a strategic entrepreneurial mindset. The three key factors that boost technological entrepreneurship in South East Asian nations such as Singapore, Malaysia and Thailand would pertain to value generation, independence and leveraging opportunities [14].

The analysis of the secondary data took several aspects into consideration to ascertain the contribution of technological entrepreneurship to economic development. These factors comprised of; high-tech exports, employment, exports, tax revenues, patent by technologies, research and development and the impact on economic growth.

From the analysis of the secondary data, it is evident that, the average rate of growth in GDP in Singapore is comparatively higher than Thailand and Malaysia. The economy in Singapore was on an upward trend during the first quarter of 2018 and this growth is directly attributed to a growth in the manufacturing sector and also to wider gains on modern techno- 
based services [41]. In the current year 2018, growth of GDP in Singapore is expected to touch around $2.5-3.5 \%$. A moderate growth is expected in the manufacturing sector while the major contribution to GDP will be from technological service. This indicates the increase in global demand for precision engineering products, electronics and IT based services. Similarly, the growth in external demand is directly attributed to the manner in which the economy in Singapore is being boosted through digital transformation.

GDP growth in Malaysia looks promising but when compared to Singapore, it is moderate. However from a global perspective, it continues to remain robust. The Malaysian economy was expected to growth by 4\% during 2016-17 [35]. This growth has been effected mainly by technological entrepreneurship and through prudent fiscal and monetary policies that helped in sustaining the growth and retain economic resilience from any external shocks [12]. In the case of Thailand, GDP growth had suffered a setback due to the global financial crisis however, an increase in economic activities especially technopreneurial activities gave a boost to GDP. A 3.2\% growth in GDP was expected in the year 2017 [12].

\subsection{Employment Rate}

The growth in technological entrepreneurship in Singapore has created tremendous employment opportunities for technical graduates in Singapore. The growth in technological entrepreneurship has spawned the demand for graduates from the technological feed who are presented with ample opportunities for employment [13]. A growth in the demand for human resources was ably supported by the several technical education institutes that exist in Singapore. The tertiary education system in Singapore is quite robust and comprises of polytechnics, universities which provides training to middle level professionals and grooms them to support the economic and technological development of the nation [28]. A wide network of institutes for technical education duly supported by an array of vocational training programmes that are industry relevant also contributes substantially which further fuels the economic growth of the nation [25].

Malaysia is behind the South East Asian nation of Singapore in terms of employment, skill levels and education. However, the growth in technological entrepreneurship has had an impact on employment levels in the nation [34]. This is attributed to strong initiatives by the Malaysian government to improve technological education that facilitates their overall economic growth and fuels further national development. With the growth in technological entrepreneurship, there has been an increase in demand for skilled technical workforce which is aptly supported by the Malaysian government's initiatives towards higher education. The government has established several new colleges to reinvent the engineering, technology and science education systems by amalgamating vocational education within tertiary and secondary education. All these factors have worked in its favor.

Though the rate of employment is low in Thailand but driven by technological entrepreneurship, there is an increase in demand for employment. The government in Thailand has recognized this demand and has undertaken initiatives to empower individuals with technical education to cater to the growing demand for employment in the technological sector [34]. The government has facilitated privatization of education, motivated the integration of information technology within the existing curriculum to develop a workforce that will be technically efficient to meet the growing employment demands [35].

\subsection{HI-Tech Exports}

Exports from the South East Asian regions like Singapore, Malaysia and Thailand has grown substantially owing to the growth of technological entrepreneurship in the said three regions. The industrial policy in Thailand which is governed by the Ministry of Industry recognized 
the potential and focused on prioritizing export promotion and attracting foreign direct investments. But later there was a shift of focus to exports as the nation realized that more focus on foreign direct investment would undermine the need for developing Thailand's individual technological abilities. There is a positive association between technological entrepreneurship and export performance in Thailand which is duly supported by diverse arguments. First and foremost, organization that are driven by technological entrepreneurship stand to gain higher gains in efficiency by pioneering innovations in process and realize higher variation by product innovation [26]. Second, technological entrepreneurship is instrumental in ensuring that organizations realize a superior level of international performance to successfully compete in the global market [33].

In Malaysia, technological entrepreneurship has an intrinsic role to play where it not only boosts exports but it also augments organizational performance. As per existing evidence, it is clear that exports emerge as a mediating variable between organizational performance and technological entrepreneurship. Size of the organization also influences organizational performance, product capabilities and exports too [31]. Singapore too is known for its hi-tech exports which are again driven by technological entrepreneurship. This association between hi-tech exports and technological entrepreneurship is based on the fact that Singapore has been quite successful in leveraging the potential of technology for product innovation which is then exported to other parts of the globe.

\subsection{Patents by Technologies}

The patenting performance in Malaysia is mixed. The number of patents granted to people who have been residing in Malaysia has witnessed a marked growth from 2000 and a recent improvement in domestic patents is largely attributed to technological entrepreneurial acumen and incentive schemes for registering patents that are available with government research institutes and universities [7]. A large number of patents are provided to organizations within Malaysia. There was a 20 fold increase in patents that were issued to people residing in Malaysia, between the period of 1995 to 2008. Nonetheless, a comparison with patent rates of other non-South East Asian nations reveals that the patent by technology rates is low in Malaysia but higher as compared to South East Asian nations such as Singapore and Thailand. As a matter of fact, the improvement in Malaysia's patent by technology records is said to be ranked second amongst Association of South East Asian Nations (ASEAN) [28].

Singapore on the other hand occupied the fourth position in terms of patenting propensity amongst ASEAN during 2009. Singapore is said to have 132 US patents for every million population which has increased by 105 during 2005 [38]. A survey conducted on intellectual property (IP) innovation during 2005 revealed that compared to the degree of technological evolution, the degree of patents were still low in Singapore. Around 60\% organizations were said to have some kind of IP while only one-third had applied for patents. As compared to Malaysia and Singapore the rate of patent by technologies in Thailand is quite low from a per capita ratio, around half of that of Malaysia. However, with technological entrepreneurship on an upward trend, the number of patents is expected to increase [39].

\subsection{Research and Development}

Technological entrepreneurship in Singapore, Malaysia and Thailand has been instrumental in driving techno-based research and development in these South East Asian nations. The growth of technological organizations along with innovations in product development has spurred the governments in these nations to spend more on research and development activities [32]. The governments in these nations are also providing tax incentives for research and development activities. In Thailand, incentives on research and development in provided 
to organizations whose investments toward research and development or research and development design amount to around $1-2 \%$ of their total sales [19]. On the whole, the situation is quite favourable as research and developments facilitates technological innovations which in turn can lead to product innovation leading to exports and thus augmenting the revenue for the organization while boosting the economy on the whole [32].

\subsection{Tax Revenues}

The increase in technological entrepreneurship in Thailand, Malaysia and Singapore has boosted the economic development in these South East Asian nations. With the increase in number of technological entrepreneurs and hi-tech exports, these nations were trading with other nations across the world. The hi-tech exports from these nations generated higher revenues [40]. To further boost technological entrepreneurship in these regions, the nations were generating a substantial amount by way of revenues from tax. This was another factor that drove technological entrepreneurship as nations stood to gain revenues from tax which led to economic development of the nation [41].

\section{CONCLUSION AND DISCUSSION}

This research intended to find how technological entrepreneurship played a critical role in economic development of South East Asian nations like Singapore, Malaysia and Thailand. Key variables within technological entrepreneurship were identified which were said to contribute to economic development through technological entrepreneurship. From this research, it is clear that technological entrepreneurs relate with entrepreneurial ecosystems in a robust manner. Each of the variables identified played a critical role in economic development and it has been clearly indicated through the findings of this research how each variable is intrinsically associated with economic development and technological entrepreneurship. The research confirms the fact that there are several empirical foundations for policies that contribute to boost innovation and technological entrepreneurship while fostering economic growth in the South East Asian nations. However, there is also a need to further enhance the policies related to technological entrepreneurship in view of the fact that every technological entrepreneurial activity might not drive growth.

\section{REFERENCES}

[1] C. Ciobanu and D. Bejou, "Forging New Global Alliances: Emerging Markets and Advanced Economies," J. Relatsh. Mark., vol. 8, no. 4, pp. 280-298, Nov. 2009.

[2] D. Valliere and R. Peterson, "Entrepreneurship and economic growth: Evidence from emerging and developed countries," Entrep. Reg. Dev., vol. 21, no. 5-6, pp. 459-480, Sep. 2009.

[3] E. Weber, "Regional and outward economic integration in South-East Asia," Appl. Econ., vol. 44, no. 10, pp. 1271-1283, Apr. 2012.

[4] S. Nistor, V.-I. Mera, and M. I. Pop Silaghi, "Is education important in assessing the impact of institutions on economic growth in emerging economies?," Appl. Econ., vol. 50, no. 34-35, pp. 3840-3854, Jul. 2018.

[5] T. Huxley, "The development of Singapore and Malaysia in regional context," Pacific Rev., vol. 7, no. 3, pp. 349-350, Jan. 1994.

[6] P. Régnier, "Perspectives From Development Economics: The Case of Southeast Asia," $J$. Curr. Southeast Asian Aff., vol. 25, no. 4, pp. 73-82, 2006.

[7] Q. T. K. Nguyen and A. M. Rugman, "Multinational subsidiary sales and performance in South East Asia," Int. Bus. Rev., vol. 24, no. 1, pp. 115-123, Feb. 2015. 
Technological Entrepreneurship for Economic Development in South East Asian Countries - A Case of Malaysia, Singapore and Thailand

[8] S. Kassim, "Islamic finance and economic growth: The Malaysian experience," Glob. Financ. J., vol. 30, pp. 66-76, May 2016.

[9] A. Chemsripong, Sujinda; Mahmood, "Services exports: an evolution and evaluation of Thailand's services exports in the context of ASEAN-5," Int. Bus. Econ. Res. J., vol. 7, no. 9, pp. 27-34, 2008.

[10] E. Badzińska, "The Concept of Technological Entrepreneurship: The Example of Business Implementation," Entrep. Bus. Econ. Rev., vol. 4, no. 3, pp. 57-72, 2016.

[11] C. M. Nacu and S. Avasilcăi, "Environmental Factors Influencing Technological Entrepreneurship: Research Framework and Results," Procedia - Soc. Behav. Sci., vol. 109, pp. 1309-1315, Jan. 2014.

[12] T. H. Byers, R. C. Dorf, and A. Nelson, Technology Ventures: From Idea to Enterprise, 4th ed. UK: McGraw-Hill Education, 2014.

[13] B. Antoncic and I. Prodan, "Alliances, corporate technological entrepreneurship and firm performance: Testing a model on manufacturing firms," Technovation, vol. 28, no. 5, pp. 257265, May 2008.

[14] M. Sultana and K. A. Ibrahim, "Creation of ASEAN Economic Community ( AEC ) For Future Automotive Industry,” J. Bus. Manag., vol. 16, no. 4, pp. 61-65, 2014.

[15] S. Sindakis, "Entrepreneurial Rise and Technological Innovation in Southeast Asia," in The Entrepreneurial Rise in Southeast Asia, New York: Palgrave Macmillan US, 2015, pp. 3-8.

[16] F. Yahya, Z. Y. Chang, and Y. H. Ng, "Developing high-tech companies in Singapore," J. Gen. Manag., vol. 42, no. 1, pp. 5-22, Sep. 2016.

[17] B. Roxas, "Effects of entrepreneurial knowledge on entrepreneurial intentions: a longitudinal study of selected South-east Asian business students," J. Educ. Work, vol. 27, no. 4, pp. 432453, Jul. 2014.

[18] S. Abdullah and A. Lahsasna, The Understanding of Technology Entrepreneurship According to Shariah Principles. 2018.

[19] S. Suradi, R. M. Yasin, and M. S. Rasul, "Increasing technopreneurs for a developing a nation: The majlis amanah rakyat (MARA) experience," J. Tech. Educ. Train., vol. 9, no. 1, pp. 73-86, 2017.

[20] S. Abdullah and A. Muhammad, "The development of entrepreneurship in Malaysia: State-led initiatives," Asian J. Technol. Innov., vol. 16, no. 1, pp. 101-116, Jan. 2008.

[21] N. H. Le, “(THESIS) Innovation and Economic Growth in Malaysia,” Lund University, 2015.

[22] S. A. Azizan, "Strengthening Malaysia's Scientific and Technological Development through Human Capital Development," Procedia - Soc. Behav. Sci., vol. 91, pp. 648-653, Oct. 2013.

[23] M. G. Mohd Yunos, "Building an innovation-based economy: The Malaysian technology business incubator experience," J. Chang. Manag., vol. 3, no. 2, pp. 177-188, Jul. 2002.

[24] S. E. Committee, The Singapore economy, new directions. Ministry of Trade \& Industry, Republic of Singapore, 1986.

[25] L. T. Chia, B. S. Lee, and C. K. Yeo, "Information technology and the Internet: The Singapore experience,” Inf. Technol. Dev., vol. 8, no. 2, pp. 101-120, Jan. 1998.

[26] P. T. Ng, "The quest for innovation and entrepreneurship in Singapore: strategies and challenges," Glob. Soc. Educ., vol. 10, no. 3, pp. 337-349, Sep. 2012.

[27] H. K. Tang and K. T. Yeo, "Technology, entrepreneurship and national development: lessons from Singapore,” Int. J. Technol. Manag., 1995. 
[28] C. Baimai and A. Mukherji, "International entrepreneurial culture of Thai SMEs," J. Glob. Entrep. Res., vol. 5, no. 1, p. 24, Dec. 2015.

[29] N. Sukasame, T. C. Sebora, and A. Mohedano-Suanes, "E-commerce entrepreneurship as a national priority: the case of Thailand," Serv. Ind. J., vol. 28, no. 7, pp. 989-1001, Sep. 2008.

[30] H. Gray and L. Sanzogni, "Technology Leapfrogging in Thailand: Issues for the Support of eCommerce Infrastructure," Electron. J. Inf. Syst. Dev. Ctries., vol. 16, no. 1, pp. 1-26, Jan. 2004

[31] A. Colovic and O. Lamotte, "Technological Environment and Technology Entrepreneurship: A Cross-Country Analysis," Creat. Innov. Manag., vol. 24, no. 4, pp. 617-628, Dec. 2015.

[32] W. G. Huff, The economic growth of Singapore. Cambridge: Cambridge University Press, 1994.

[33] J. Othman, Y. Jafari, and T. Sarmidi, "Economic growth, foreign direct investment, macroeconomic conditions and sustainability in Malaysia," Appl. Econom. Int. Dev., 2014.

[34] I. Ekpe, R. Che Razak, M. Ismail, and Z. Abdullah, "Entrepreneurial Skill Acquisition and Youth's Self-Employment in Malaysia: How Far?," Mediterr. J. Soc. Sci., vol. 6, no. 4, pp. 150-154, 2015.

[35] S. Siriprachai, "Export-Oriented Industrialisation Strategy with Land-Abundance:Some of Thailand's Shortcomings," Thammasat Econ. J., vol. 16, no. 2, pp. 83-138, 1998.

[36] P. N. Figueiredo, "Learning, capability accumulation and firms differences: evidence from latecomer steel," Ind. Corp. Chang., vol. 12, no. 3, pp. 607-643, 2003.

[37] V. G. R. Chandran and R. Rasiah, "Firm size, technological capability, exports and economic performance: the case of electronics industry in Malaysia," J. Bus. Econ. Manag., vol. 14, no. 4, pp. 741-757, Sep. 2013.

[38] A. Gani, "Technological Achievement, High Technology Exports and Growth," J. Comp. Int. Manag., vol. 12, no. 2, pp. 31-47, 2009.

[39] M. Lai and S. Yap, "Technology Development in Malaysia and the Newly Industrializing Economies : A Comparative Analysis," Asia-Pacific Dev. J., vol. 11, no. 2, pp. 53-80, 2004.

[40] R. P. J. Rajapathirana and Y. Hui, "Relationship between innovation capability, innovation type, and firm performance," J. Innov. Knowl., vol. 3, no. 1, pp. 44-55, Jan. 2018.

[41] A. Degelsegger and F. Gruber, Spotlight on: Stimulating innovation in Southeast Asia Spotlight on : Stimulating innovation in Southeast Asia. 2014. 